\title{
INCLUSÃO DE TECNOLOGIAS DE INFORMAÇÃO E COMUNICAÇÃO EM ESCOLAS PÚBLICAS DE TERRA ROXA (SP).
}

\author{
Rosemara Perpetua LOPES ${ }^{1}$ \\ Vanessa MASITELI ${ }^{2}$ \\ Eloi FEITOSA ${ }^{3}$
}

\begin{abstract}
RESUMO: Neste trabalho, apresenta-se o relato de uma experiência de uso de applets em escolas da cidade de Terra Roxa (SP), com os objetivos de incluir Tecnologias de Informação e Comunicação (TIC) na escola pública ampliando as chances de aprendizagem dos alunos em Matemática e contribuir para evitar a exclusão digital do cidadão em idade escolar. As atividades foram criadas e continuamente avaliadas por um grupo interdisciplinar de uma universidade pública do interior paulista, sendo desenvolvidas na Sala Ambiente de Informática (SAI) das escolas contatadas por uma professora de Matemática e técnicos de Informática. A proposta envolveu a aprendizagem de conceitos matemáticos tais como funções e equações. Os relatórios semanais enviados via e-mail apresentam aspectos positivos, como motivação dos alunos para a aprendizagem matemática e participação ativa dos mesmos na construção do próprio conhecimento, e aspectos negativos, como interrupção das atividades por motivos como reuniões, eventos ou problemas técnicos e dificuldade do professor com o inglês. Os resultados obtidos autorizam a afirmar que em condições favoráveis, as TIC podem favorecer a educação escolar sob vários aspectos, permitindo que a ação educativa se realize em novos espaços de aprendizagem.
\end{abstract}

PALAVRAS-CHAVE: Tecnologias de informação e comunicação. Aprendizagem matemática. Applets.

\section{Introdução}

Neste trabalho, apresenta-se uma das realizações de uma proposta mais ampla que envolve o uso de tecnologias como computador e applets ${ }^{4}$ em ambientes de ensino de escolas públicas de ensino fundamental e médio. Os objetivos de tal proposta são: incluir Tecnologias de Informação e Comunicação (TIC) ${ }^{5}$ nas escolas públicas, ampliando as chances de

\footnotetext{
${ }^{1}$ Mestranda em Educação. UNESP - Universidade Estadual Paulista. Faculdade de Ciência e Tecnologia Programa de Pós-graduação em Educação. Presidente Prudente - SP - Brasil. 19060-900 rosemara@ibilce.unesp.br

${ }^{2}$ Graduanda em Matemática. UNESP - Univesidade Estadual Paulista. Instituto de Biociências, Letras e Ciências Exatas - Departamento de Matemática. São José do Rio Preto - SP - Brasil. 15054-000 vanmasi@gmail.com

${ }^{3}$ UNESP - Universidade Estadual Paulista. Instituto de Biociências, Letras e Ciências Exatas - Departamento de Física. São José do Rio Preto - SP - Brasil. 15054-000 - eloi@ibilce.unesp.br

4 Tecnicamente, applets são programas computacionais que podem ser incluídos em uma página HTML. Requerem os aplicativos Java, Flash e Shockwave disponíveis gratuitamente na Internet. Na prática, atribuímos o nome applets a todas as animações virtuais que utilizamos.

${ }^{5} \mathrm{O}$ termo Tecnologias de Informação e Comunicação (TIC) abarca mídias, Informática, Internet, enfim, tudo quanto se refere a meios de informação e comunicação de massa (aqueles acessíveis à maioria da população,
} 
aprendizagem de Matemática do alunado e contribuir para evitar a exclusão digital do cidadão em idade escolar.

Trata-se do relato de uma experiência de uso de simulações virtuais e jogos que abordam conteúdos de Matemática junto a alunos da oitava série do ensino fundamental ${ }^{6}$ de duas escolas públicas da cidade de Terra Roxa, situada no interior paulista. As atividades foram planejadas, criadas e continuamente avaliadas por um grupo interdisciplinar de uma universidade pública de São José do Rio Preto (SP), constituído por alunos de graduação em Matemática, Ciências Biológicas e Ciências da Computação, uma mestranda em Educação e o coordenador, professor de Física.

As atividades relatadas foram desenvolvidas na Sala Ambiente de Informática (SAI) por duas professoras de Matemática que atuaram como coordenadoras locais e pelos técnicos de Informática das escolas públicas contatadas. Envolveram a aprendizagem de conceitos matemáticos, tais como funções e equações, sendo a escolha destes conteúdos justificada pela dificuldade que os alunos demonstram ter para aprendê-los e pelo fato de os mesmos serem abordados num nível de complexidade ampliado nos anos escolares subseqüentes, isto é, no ensino médio.

\section{O desafio de ensinar e aprender Matemática nos anos de educação básica}

Ensinar e aprender Matemática continua sendo um desafio para professores e alunos do ensino fundamental e médio. Como superá-lo? Como motivar o aluno para a aprendizagem Matemática, facilitando sua aprendizagem?

Segundo Teixeira (2004), as “provas” matemáticas se apóiam em axiomas (verdades já estabelecidas) e os conceitos matemáticos se formam por dedução e não por indução. $O$ pensamento matemático é resultado de abstrações e expresso em uma linguagem específica. O conhecimento matemático é dependente de uma linguagem sintética, formal e universal. “A aprendizagem de conceitos matemáticos é de natureza lógico-matemática e não empírica [...]” (TEIXEIRA, 2004, p.05), de modo que a evolução do pensamento matemático depende da passagem de representações analógicas e intuitivas para representações analíticas que utilizam códigos mais abstratos e menos intuitivos, sendo o componente lógico-verbal condição necessária, embora não suficiente, para a aprendizagem matemática.

como televisão e rádio) ou não (como as tecnologias digitais). Na educação, as TIC são novas tecnologias que não se confundem com as "velhas", sendo estas: lousa, caderno lápis, caneta, livros didáticos etc.

${ }^{6}$ As escolas públicas contatadas adotam, ainda, a nomenclatura "séries” ao invés de "anos” escolares. 
Ainda segundo Teixeira (2004), no processo de ensinar e de aprender, é necessário considerar o ritmo de aprendizagem de cada sujeito aprendiz. Nesse sentido, recentemente, os ditos erros passaram de algo negativo a ser evitado a elementos constitutivos do processo de construção do conhecimento. Os erros são indicadores do mecanismo próprio de construção dos esquemas mentais que se constituem e ganham significado quando se enfrenta novas situações no meio externo ${ }^{7}$. A autora, assim, considera que a origem dos erros está na natureza dos conceitos matemáticos, na forma de ensina-los ou nas condições do aluno para aprender.

O ensino da Matemática segue um modelo padrão perpetuado pela tradição escolar, caracterizado pela dissociação dos aspectos sintáticos e semânticos (aspectos indissociáveis) e pela utilização da resolução de problemas como um método (como um fim em si mesmo e não como forma de investigação). Os aspectos básicos (sintático e semântico) devem ser equacionados para o ensino de Matemática, cabendo ao professor essa articulação, mediante a clareza dos principais obstáculos que cada conceito apresenta. Conceitos específicos requerem metodologias específicas. Ensinar Matemática é fazer ao aluno um convite à abstração, buscando equilíbrio entre o conhecimento cotidiano e o formal (TEIXEIRA, 2004).

As conceituações de Teixeira (2004) indicam que a Matemática é um conhecimento específico que requer raciocínio lógico-formal para a aprendizagem. Entretanto, as aulas de matemática do tipo tradicional (MIZUKAMI, 1986) parecem não dar conta de facilitar o desenvolvimento desse raciocínio. Práticas educativas calcadas numa abordagem tradicional de ensino limitam as chances de aprendizagem dos alunos da escola pública. O desinteresse aliado à falta de conhecimento matemático prejudica a aprendizagem do aluno em ciências como a Física, por exemplo. Nesse contexto, as TIC surgem como uma opção metodológica nada desprezível, podendo assumir a função de organizadores prévios no processo de aprendizagem escolar, conforme previsto por Ausubel (MOREIRA, 1985).

A organização do ensino para uma aprendizagem significativa consiste em identificar conceitos básicos da matéria e os modos de estruturação desses conceitos. O desenvolvimento de conceitos é facilitado quando elementos gerais e inclusivos de um conceito são introduzidos no processo. A teoria ausubeliana está voltada à clareza e à estabilidade da estrutura cognitiva, de modo que idéias menos gerais e inclusivas sejam aprendidas significativamente e idéias mais gerais adquiram clareza e estabilidade,

\footnotetext{
${ }^{7}$ Nesta passagem, Teixeira referiu-se aos esquemas mentais previstos pela teoria piagetiana. Para saber mais a respeito, conferir: Ramozzi-Chiarottino (1988).
} 
configurando-se como conceitos subsunçores. Nesse processo, o material utilizado e a disponibilidade do aluno em aprender são fundamentais (AUSUBEL; NOVAK; HANESIAN, 1980).

\section{A Matemática em ambientes virtuais de aprendizagem}

Nos dias atuais, as TIC estão presentes tanto em ambientes familiares quanto em ambientes profissionais em geral (CARNEIRO, 2002). Mas a sua inserção na escola tem sido dificultada por vários fatores, um deles é a cultura escolar. Segundo Costa (2008), a cultura interna de algumas escolas pode favorecer ou não a inserção e a utilização das TIC em ambientes escolares. Para o autor, a utilização das TIC na escola implica uma ruptura com a cultura profissional tradicional.

Crianças e jovens estão cada vez mais familiarizados com tecnologias digitais como computadores, celulares, videogames etc., porém, utilizam-nas para entretenimento somente. Visando a contribuir para o uso de tecnologias digitais nas escolas um grupo interdisciplinar composto por estudantes de graduação e de pós-graduação de uma universidade pública do interior paulista cria materiais para a inclusão de applets (animações por computador usando Java ou outros aplicativos) juntamente com propostas de utilização dos mesmos para fins didáticos, oferecendo novas ferramentas que auxiliem o aluno a superar dificuldades de aprendizagem em áreas como a Matemática.

Simulações computacionais são uma das modalidades de uso do computador para fins educacionais (GOMES, 2002; FIOLHAIS; TRINDADE, 2003). Elas têm suas limitações (MEDEIROS; MEDEIROS, 2002; VALENTE, 1999). Por isso, carecem do acompanhamento do professor em todo o processo educativo. Inseridas em situações de aprendizagem, as simulações, animações ou jogos virtuais possibilitam a construção de conhecimentos pelo aluno, aproximando-o do objeto de aprendizagem.

No caso da aprendizagem matemática, o ambiente virtual tem possibilidades variadas, permitindo a visualização de uma idéia antes apenas mentalizada a partir da fala do professor em sala de aula. Além das possibilidades pedagógicas, um outro fator favorável à incorporação das TIC é a necessidade de se evitar a exclusão digital dos alunos que freqüentam a escola pública, promovendo a democratização do acesso a novas linguagens como a digital, para que não tenhamos, no futuro, cidadãos sobrantes desconectados (KUENZER, 2001). 
Explicitados esses pressupostos, apresenta-se a realização de uma ação concreta realizada em escolas públicas envolvendo o uso de TIC na aprendizagem matemática.

\section{TIC na aprendizagem matemática: realização de uma ação educativa}

A ação educativa apresentada a seguir envolveu alunos de oitava série, uma professora de Matemática e dois técnicos de Informática de duas escolas públicas da cidade de Terra Roxa (SP). O material utilizado nessas escolas foi previamente elaborado em ambiente universitário. Os conteúdos matemáticos abordados nas atividades desenvolvidas nas SAI foram indicados pelas professoras de Matemática. Por opção da escola, essas professoras não são as mesmas que ministram aulas aos alunos nas salas de aula cotidianamente; são outras, especialmente designadas para o desenvolvimento da proposta de aprendizagem de Matemática por meio de TIC, mas a comunicação entre a professora de Matemática da SAI e as efetivas professoras de Matemática das turmas é constante. O mecanismo utilizado para acompanhar o desenvolvimento das atividades na escola foi o envio semanal de relatórios via e-mail.

O material criado para as escolas contém applets inseridos numa proposta didática flexível, que compreende: contextualização histórica do conceito abordado, resolução de problemas em ambiente virtual e reconhecimento do conceito em situações do cotidiano do aluno, tudo isso para que o conteúdo ensinado faça sentido ao aluno favorecendo sua apredizagem. Juntamente com os applets seguem orientações sobre o funcionamento dos mesmos e seus recursos e também traduções inglês-português. Nas SAI, semanalmente são desenvolvidas atividades sobre conteúdos matemáticos variados. Dois deles foram selecionados para serem apresentados neste trabalho.

\section{Seleção de applets para o estudo de funções e frações}

O conhecimento matemático pode ser construído com o auxílio de simulações e jogos virtuais. No caso de funções e frações, algumas opções são:

A maquina de funções - facilita a aprendizagem por meio da experimentação de várias funções, de modo que o aluno informa o valor da variável e a "máquina de funções” fornece o valor da função. Este valor permitirá ao aluno inferir qual a função responsável pela operação que está realizando. 
Funções polinomiais - permite visualizar funções polinomiais do tipo $y=a x^{2}+b x+$ $c$, onde as constantes $a, b$ e $c$ são ajustáveis, possibilitando observar o comportamento da curva ao representar a função para diferentes valores dessas constantes.

Balança algébrica 1 - permite resolver uma equação linear simples com o auxílio de uma balança. Possibilita realizar qualquer operação aritmética com números inteiros e múltiplos de $x$, com o objetivo de obter um único bloco $x$ de um lado da balança e um número inteiro do outro lado. O valor numérico obtido é a solução da equação.

Balança algébrica 2 - permite encontrar e visualizar graficamente soluções de equações lineares do primeiro, segundo ou terceiro graus. O aluno é estimulado a variar os parâmetros da equação e a observar, por exemplo, que para certos valores não existe solução real da equação, ou seja, as curvas não se cruzam.

Gráfico de funções - permite visualizar até três funções no gráfico em cores diferentes, clicando em functions e sobre $g(x)$ ou $h(x)$ e, em seguida, entrando com a função desejada. Esta animação permite também restringir o domínio da função.

Os applets acima apresentados foram utilizados nas escolas contatadas. O grau de dificuldade dos mesmos aumenta do primeiro ao último. Juntos, eles permitem relacionar os conceitos de função e de equação e orientar os alunos para soluções analíticas e gráficas de equações.

Manipulando applets como esses, o aluno pode "perceber" melhor conceitos matemáticos como os de função e equação. Entretanto, repetimos algo dito anteriormente: em si mesmos, esses aplicativos pouco significam aos alunos; é preciso que estejam inseridos em situações de aprendizagem e que sejam utilizados mediante a orientação e acompanhamento de um professor de Matemática.

Um outro aspecto a ressaltar é o dos conhecimentos prévios dos alunos a respeito de funções e equações. No caso dos alunos da oitava série das escolas de Terra Roxa, o conteúdo em questão havia sido abordado previamente em sala de aula pelo professor das turmas. Portanto, esses alunos já tinham algum conhecimento acerca do assunto tratado quando participaram das atividades com applets na SAI.

\section{Resultados da atividade didática com applets}

Conforme dito antes, o acompanhamento do desenvolvimento das atividades envolvendo o uso de applets nas escolas da cidade de Terra Roxa foi realizado por meio de relatórios semanais enviados por e-mail pela professora de Matemática que, juntamente com o 
técnico de Informática de cada escola, atuou na SAI. Com base nesses relatórios, o material didático foi elaborado semanalmente para utilização de alunos da oitava série do ensino fundamental.

Nesses relatórios, as professoras apontam aspectos favoráveis e aspectos contrários ao desenvolvimento da atividade. De modo geral, um complicador apontado pela professora que desenvolveu as atividades junto às oitavas séries é o inglês, idioma que a professora não domina. O inglês presente nas animações pode se constituir num fator motivador da aprendizagem dessa língua estrangeira ou num fator complicador, quando não há quem tire as dúvidas dos alunos a respeito.

Além do inglês, um outro fator que dificulta o desenvolvimento de atividades com applets é a participação dos alunos em atividades relacionadas a datas comemorativas e outros eventos. A este respeito, num dos relatórios enviados, a professora relatou que a atividade não foi realizada porque houve reunião de pais. Numa data anterior, a atividade havia sido suspensa em função da realização de uma passeata contra a dengue. E assim sucessivamente.

O desenvolvimento das atividades com applets na SAI foi dificultado também por eventos de ordem técnica. Num dos relatórios, a professora relatou que não foi possível realizar a atividade planejada por problemas de conexão com a Internet. Num outro, relatou que não houve atividade com duas das turmas, porque faltou energia elétrica na escola. Também o número de alunos por computador na SAI (dois alunos por micro) comprometeu o desenvolvimento das atividades em algumas ocasiões.

Além do inglês, da excessiva participação dos alunos em eventos extra-curriculares e dos problemas de natureza técnica, a falta de familiaridade do professor com recursos tecnológicos, as aparentes concepções que eles têm sobre o que é ensinar e o que é aprender e a visão que professores, coordenadores e diretores em geral têm sobre o que são e para que servem as TIC na escola atuaram como fatores contrários ao satisfatório desenvolvimento das atividades com applets.

Sobre a atividade com funções e equações especificamente, o professor relatou que, ao desenvolver a atividade numa das escolas com uma das turmas, constatou que os alunos tinham dificuldades com decimais, conteúdo curricular do quinto ano escolar. Motivados pelo desafio proposto pelo jogo ou pelo applet, os alunos manifestaram dúvidas e solicitaram o auxílio do professor, sendo este um aspecto positivo da experiência relatada. Tomando a teoria ausubeliana como parâmetro (MOREIRA, 1985), considera-se que esses alunos se mostram-se pré-dispostos à aprendizagem, o que, por si só, representa um ganho no processo educativo. 
Buscando tornar a aprendizagem significativa nos momentos em que o aluno está na SAI, inseriu-se na atividade elementos históricos e/ou cotidianos que pudessem assumir o papel dos conceitos subsunçores previstos por Ausubel, conceitos a partir dos quais o aluno pode construir o seu conhecimento. Em seus relatos, a professora de Matemática aponta não somente as dificuldades, mas também o interesse dos alunos pelos applets (jogos e animações) e algumas de suas conquistas no campo da aprendizagem.

Em suma, em seus relatos, a professora indicou aspectos positivos e negativos verificados durante o desenvolvimento das atividades. São aspectos positivos: a motivação dos alunos para a aprendizagem de Matemática; a participação ativa do aluno na construção de seu próprio conhecimento; o interesse dos alunos pelo aspecto audiovisual (cores, formas, movimento, som etc.) dos applets etc. São aspectos negativos: a interrupção das atividades por motivos como reuniões, eventos ou problemas técnicos; a dificuldade do professor com o inglês etc.

\section{Considerações finais}

As atividades desenvolvidas junto a alunos de oitava série das escolas públicas de Terra Roxa (SP) foram concluídas no final do primeiro semestre de 2009 tendo sido bem sucedidas, a julgar pelo pedido dos professores e dirigentes para que sejam mantidas no segundo semestre deste mesmo ano.

As atividades com fuções e equações são apenas parte de um trabalho mais amplo, pelo qual se pretende evitar ou, ao menos, minimizar a exclusão digital de crianças e jovens numa época em que os meios de informação e comunicação contribuem para alterar significativamente os modos de ser e de viver da sociedade atual (TEDESCO, 1998), maximizando suas chances de aprendizagem matemática. Nesse sentido, o apresentado neste trabalho autoriza a afirmar que, em condições favoráveis, as TIC podem favorecer a educação escolar sob vários aspectos, permitindo que a ação educativa se realize em novos espaços de aprendizagem. 


\title{
INFORMATION AND COMMUNICATION TECHNOLOGIES (ICT) IN PUBLIC SCHOOLS OF TERRA ROXA CITY
}

\begin{abstract}
In this work, it is reported an experiment of using applets in schools of Terra Roxa (SP), aiming to include Information and Communication Technologies (ICT) in public schools, thus increasing the chances of student learning in Mathematics and help prevent digital exclusion of citizens of school age. The activities were created and continuously evaluated by an interdisciplinary group of a public university in São Paulo State, being developed in the Computer Room Environment (IAS) of the contacted schools by a professor of mathematics and technicians in informatics. The proposal involved the learning of mathematical concepts such as functions and equations. The weekly reports sent via e-mail have positive aspects, such as students motivation for learning mathematics and their active participation in the construction of their own knowledge, and negative aspects, such as interruption of activities for reasons such as meetings, events or technical problems and the teacher difficulty with the English idiom. The results allow one to say that under favorable conditions, ICT can facilitate the school in many ways, allowing the educational activity to take place in new spaces for learning.
\end{abstract}

KEYWORDS: Information and communication Technologies. Mathematic learning. Applets.

\section{REFERÊNCIAS}

AUSUBEL, D. P.; NOVAK, J. D.; HANESIAN, H. Psicologia educacional. 2. ed. Rio de Janeiro: Interamericana, 1980.

CARNEIRO, R. Informática na educação: representações sociais do cotidiano. São Paulo: Cortez, 2002.

COSTA, G. L. M. Mudanças da cultura docente em um contexto de trabalho colaborativo mediado pelas tecnologias de informação e comunicação. Perspectivas em Ciência da Informação, Belo Horizonte, v.13, n.1, p.152-165, jan./abr. 2008.

FIOLHAIS, C; TRINDADE, J. Física no computador: o computador como uma ferramenta no ensino e na aprendizagem das ciências físicas. Revista Brasileira de Ensino de Física, São Paulo, v.25, n.3, p.259-272, set. 2003.

GOMES, N. G. Computador na escola: novas tecnologias e inovações educacionais. In: BELLONI, M. L. (Org.). A formação na sociedade do espetáculo. São Paulo: Loyola, 2002. p.119-134. 
KUENZER, A. Z. Educação, linguagens e tecnologias: as mudanças no mundo do trabalho e as relações entre conhecimento e método. In: CANDAU, V. M. (Org.). Cultura, linguagem e subjetividade no ensinar e aprender. 2. ed. Rio de Janeiro: DP\&A, 2001. p.134-160.

MEDEIROS, A.; MEDEIROS, C. F. Possibilidades e limitações das simulações computacionais no ensino da Física. Revista Brasileira de Ensino de Física, São Paulo, v.24, n.2, p.77-86, jun. 2002.

MIZUKAMI, M. G. N. Ensino: as abordagens do processo. São Paulo: EPU, 1986.

MOREIRA, M. A. A teoria de aprendizagem de David Ausubel. In: MOREIRA, M. A. et al. Aprendizagem: perspectivas teóricas. Porto Alegre: Ed. da UFRGS, 1985. p.127-143.

RAMOZZI-CHIAROTTINO, Z. Psicologia e epistemologia genética de Jean Piaget. São Paulo: EPU, 1988.

TEDESCO, J. C. O novo pacto educativo: educação, competitividade e cidadania na sociedade moderna. São Paulo: Ática, 1998.

TEIXEIRA, L. R. M. Dificuldades e erros na aprendizagem da Matemática. In: ENCONTRO PAULISTA DE EDUCAÇÃO MATEMÁTICA, 7., 2004, São Paulo. Anais... São Paulo: SBEM: EPEM, 2004. p.1-14.

VALENTE, J. A. Análise dos diferentes tipos de software usados na educação. In: VALENTE, J. A. (Org.). O computador na sociedade do conhecimento. Campinas: UNICAMP: NIED, 1999. p.89-110. 